\title{
Importance of Capnography Monitoring in Critical Ill Patients
}

\author{
Young-Kown Ko
}

Department of Anesthesiology and Pain Medicine, Chungnam National University Hospital, Daejeon, Korea

Endotracheal intubation (EI) is the most commonly performed in the intensive care unit but has the potential to lead to critical complications [1]. Hence, the use of fluid loading, preoxygenation with noninvasive positive pressure ventilation, rapid sequence induction or capnography monitoring is recommended to make EI safer [2].

In this topic of The Korean Journal of Critical Care Medicine, Yoon et al. [3] reported a case "Endotracheal Tube Completely Severed by a Patient Bite and Lodged in the Right Main Bronchus." In that case, the authors had difficulty inserting a suction catheter into the endotracheal tube (ETT) and after 30 minutes, they observed ETT damage caused by increased peak airway pressure, lower tidal volumes and reduced oxygen saturation. If the patient had been monitored using a capnography, such problems could have been detected sooner.

According to a human cadaveric study, capnography is highly accurate in detecting a correct ETT placement showing 100\% sensitivity and 100\% specificity with the ability to provide highly reliable readings in low-perfusion states (cardiac arrest). Capnographic monitoring is therefore recommended as a gold standard for patients undergoing endotracheal intubation [4].

Capnography provides critical physiologic data regarding ventilation and perfusion matching in the lung, heart and metabolic rate [5]. In addition, it provides valuable patient safety information that can be used for a variety of clinical decisions, including the prediction of acute respiratory distress syndrome gradient [6], determination of outcome after cardiopulmonary resuscitation [7] and decision about esophageal intubation, unexpected extubation, disconnection of breathing circuit, the mechanical state of the lung. Therefore, the capacity of capnography can be aggressively used for monitoring critically ill patients.

\author{
Young-Kown Ko \\ Department of Anesthesiology and Pain \\ Medicine, Chungnam National University \\ Hospital, 282 Munhwa-ro, Jung-gu, \\ Daejeon 35015, Korea \\ Tel: +82-42-280-7841 \\ Fax: +82-42-280-7968 \\ E-mail: ane84@cnu.ac.kr \\ ORCID \\ Young-Kown Ko \\ http://orcid.org/0000-0002-0178-6346 \\ *No potential conflict of interest relevant to this \\ article was reported.
}




\section{References}

1. Baillard C, Fosse JP, Sebbane M, Chanques G, Vincent F, Courouble P, et al. Noninvasive ventilation improves preoxygenation before intubation of hypoxic patients. Am J Respir Crit Care Med 2006; 174: 171-7.

2. Jaber S, Jung B, Corne P, Sebbane M, Muller L, Chanques G, et al. An intervention to decrease complications related to endotracheal intubation in the intensive care unit: a prospective, multiple-center study. Intensive Care Med 2010; 36: 248-55.

3. Yoon S, Choo H, Kim SE, Kwon H, Lee H. A reinforced endotracheal tube completely severed by a patient bite and lodged in the right main bronchus. Korean J Crit Care Med 2017; 32: 70-3.

4. Silvestri S, Ladde JG, Brown JF, Roa JV, Hunter
C, Ralls GA, et al. Endotracheal tube placement confirmation: $100 \%$ sensitivity and specificity with sustained four-phase capnographic waveforms in a cadaveric experimental model. Resuscitation 2017 Jan 19 [Epub]. http://dx.doi.org/10.1016/ j.resuscitation.2017.01.002.

5. Siobal M. Monitoring exhaled carbon dioxide. Respir Care 2016; 61: 1397-416.

6. Yousuf T, Brinton T, Murtaza G, Wozniczka D, Ahmad K, Iskandar J, et al. Establishing a gradient between partial pressure of arterial carbon dioxide and end-tidal carbon dioxide in patients with acute respiratory distress syndrome. J Investig Med 2017; 65: 338-41.

7. Kodali BS, Urman RD. Capnography during cardiopulmonary resuscitation: current evidence and future directions. J Emerg Trauma Shock 2014; 7: 332-40. 